$\xi=-1$

\title{
Big Data Analysis Model for MRO Business Using Artificial Intelligence System Concept
}

\author{
Inhwan JUNG ${ }^{1}$, He SUN ${ }^{2}$, Jangmook KANG ${ }^{3}$, Choong Hyong Lee ${ }^{4}$, Sangwon LEE ${ }^{5 *}$ \\ ${ }^{1}$ Department of Computer Engineering, Hansung University, Seoul, Korea \\ ${ }^{2}$ Department of Informantion Management, Wonkwang University, Iksan, Korea \\ ${ }^{3,4}$ Department of Big Data \& Industry Security, Namseoul University, Cheonan, Korea \\ ${ }^{4}$ Department of Computer \& Software Engineering (Institute of Convergence Creativity), Wonkwang University, Iksan, Korea \\ *Corresponding author E-mail: sangwonlee@wku.ac.kr
}

\begin{abstract}
The rapidly changing environment of the shipbuilding industry has put Korea's shipbuilding industry in a crisis. The purpose of this study was to develop a business model to maintain, maintain and operate Big Data-based MRO(Maintenance, Repair, and Operation) consumables, which is expected to be the new growth engine for the domestic shipbuilding industry. Although Korean shipbuilders have world-class technologies for ship dogma, the market for ship maintenance and repair is still in its infancy. For Korean shipbuilders, MRO business can be a growth engine that will provide food for the next 30 years, but to do so, we need to make sure that everything that happens in the entire process, from ship design to maintenance and maintenance. Therefore, by systematically establishing Big Data related to components and developing MRO business models based on data analysis capabilities using Artificial Intelligence system concept, we can develop new growth engines for related industries in Ship Industry.
\end{abstract}

Keywords: AI; Big Data; Business Model; Maintenance; Operation; Repair; Ship Service

\section{Introduction}

Through the development of a Big Data-based [1, 2, 3] vessel MRO [4] service platform, MRO service to provide customers with optimal vessel maintenance/repair service is desperately needed. For this purpose, this study aims to develop Big Databased vessel MRO platform for ship MRO service industry and to validate CBM (Condition Based Maintenance) technology.

This study optimizes the industry-industry infrastructure and data resources and analytics to help identify and support customer requirements and new business opportunities, with accurate insight from existing and emerging internal information. In other words, the technology products for which customers can collect and analyze shipbuilding big business data, such as ship market, energy trend, world volume change, world ship operation data, and innovation development trend are the first products to be proposed. In particular, it will be possible to develop products that can create premium products based on data rather than wasting resources on developing technologies that customers do not want. Furthermore, we will be able to create business cases based on measurable performance, plan market-driven products and services, and continue to achieve market destructive innovation.

\section{Related Works}

This study aims to streamline the maintenance, repair, and operation of Big Data-based ships, Maintenance and Operation (MRO) consumer materials, in order to increase the growth engines of the Korean shipbuilding and marine industries.
Although Korean shipbuilders have world-class technologies for ship dogma, the market for ship maintenance and repair is still in its infancy. For Korean shipbuilders, the MRO project could be a growth engine that will provide food for the next 30 years. To do so, a management system must be established that can data and automatically procure the entire process from ship design to maintenance and repair at the end of a particular part's life. Therefore, by developing a new model of MRO business based on data analysis ability to systematically build and utilize Big Data related to components, the company can find new growth engines for related industries. Ship MRO service model development field is to establish an MRO service business model that provides optimal vessel maintenance and repair services to customers through the development of a Big Data-based shipbuilding MRO service platform.

Ship MRO is all goods and services related to maintenance, repair and operation required for the vessel to continue its normal operation. Ship MRO industry can be defined as an industry providing MRO products and services at the request of the ship owner (shipping company or ship manager). Following (Figure 1) is vessel MRO. (1) Consumable vessel supply: This feature provides a consumable for maintaining normal condition on board. (2) Supply office/spare parts: This function provides only accessories and spare parts, such as engine accessories, and repairs and replacements are carried out by on-board engineers. (3) Supply of equipment: This function provides only equipment systems or equipment products and is repaired and replaced by the onboard engineer. (4) Supply of equipment and repair services: This function is carried out by the supplier engineer as well as by the equipment systems or equipment products. (5) Supply of ship inspection/repair services: This feature provides repair services that require regular vessel inspection authorization and drydocking. 


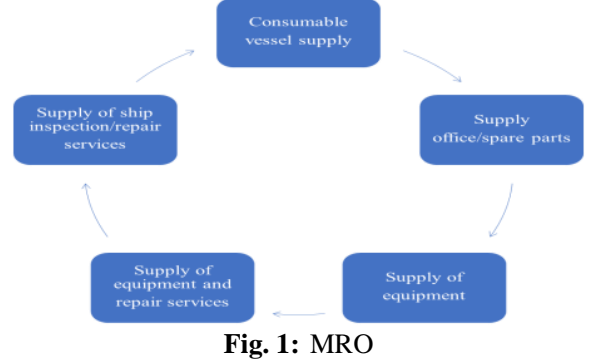

The existing MRO industry is a customer-driven business that is controlled by the customer's trading network. As a result, small and medium equipment suppliers have structural problems that can reduce their business opportunities and competitiveness. Therefore, this study proposes a new business platform using an open B2B trading platform called Smart MRO platform.

\section{Design of Smart MRO Platform}

This platform (Figure 2) aims to provide a service that enables customers and providers to win-win through Big Data technology and IT solutions.

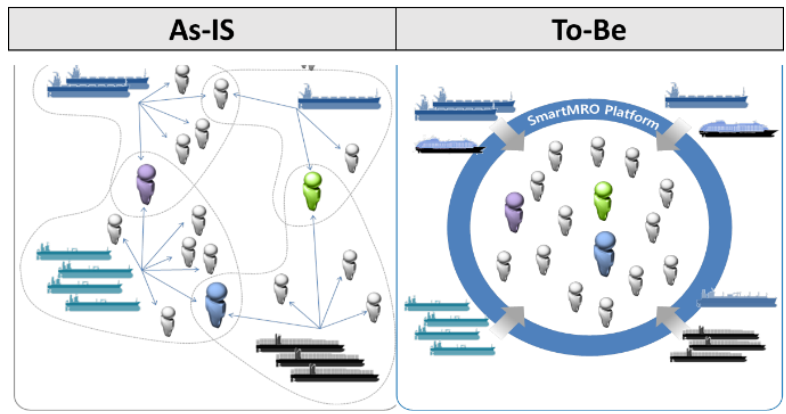

Fig. 2: As-Is vs. To-Be of MRO

This allows suppliers to increase overall MRO business opportunities based on differentiated services on the Smart MRO platform, thereby allowing small and medium suppliers to continue to grow as the market grows. In addition, customers may also have benefit to reduce costs and delivery time using an optimal MRO package when they make transactions through the platform. The development of vessel MRO service model is a task of developing a Big Data-based vessel MRO service platform to build an MRO service business model that provides optimal vessel maintenance and repair services to customers.

In this study, we proposed a new business platform using an open B2B trading platform called SMROP(Ship Maintenance, Repair, and Operation Platform). This platform aims to provide a service that enables customers and providers to win-win through Big Data technology and IT solutions. This will increase overall MRO business opportunity based on differentiated services of SMROP platform, resulting in continued growth of small and mediumsized suppliers and overseas market expansion. In addition, customers may also have benefit to reduce costs and delivery time using an optimal MRO package when they make transactions through the platform.

\subsection{Structure of Smart MRO Platform}

Four areas of the study were developed as follows (Figure 3).

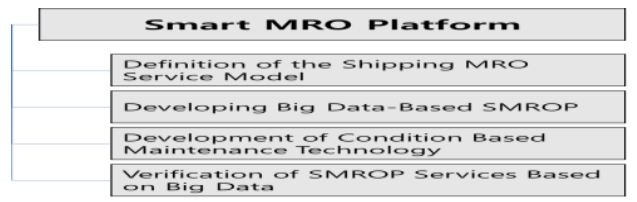

Fig. 3: Four Areas of the Study -

(1) Definition of the Shipping MRO Service Model: Activities such as benchmarking and interviewing vessel MRO industry have defined vessel MRO industry and services. It also identified the need to develop a Big Data-based SMROP to establish a model of ship MRO service in Korea.

(2) Developing Big Data-Based SMROP: SMROP based on Big Data was developed to implement ship MRO service. The platform consists largely of the service web portal, analysis module, and database.

(3) Development of Condition Based Maintenance Technology: In this study, technical verification was conducted to link the statebased maintenance technology of materials and equipment in vessels to MRO service in the future. The actual vessel operational data were analyzed to identify anomalies in advance, to construct a system that generates early warning signals, and to generate vibration characteristics artificially generated by the simulator.

(4) Verification of SMROP Services Based on Big Data: The basis for further commercialization was provided to demonstrate the model of vessel MRO service.

\subsection{Development of Smart MRO Platform}

Smart MRO platform consists of service portal, Big Data analysis module, database (DB), and is a virtual space for sharing services and information among companies related to vessel MRO (Figure 4).

The service portal is an Internet site that implements the ship's MRO service. This portal has MRO purchasing support, ship management support, information retrieval and marketing services. MRO Purchase Support Service allows buyer and supplier to receive and receive quote service and consists of simple quote request and automatic quote request. A simple quotation request is a method of designating a product and a vendor in the same way as the existing purchase method. On the other hand, an automatic quoting request is a method of entering the model name and requirements of a product and requesting various types of products at once. This automated quoting request is a concept in which an optimal vendor is found through an optimal package module, packaged and provided to the customer. The Ship Management Support Service provides information to customers by predicting and predicting tiles and items required based on purchase and service history. Through this, the service enables preventive maintenance. The information search service is designed to help companies related to the vessel MRO see their information and efficiently find the companies they need. Finally, marketing services are services provided by the platform manager to buyers. This service is a concept to estimate and promote potential customers so that preemptive marketing can take place from a customer acquisition perspective.

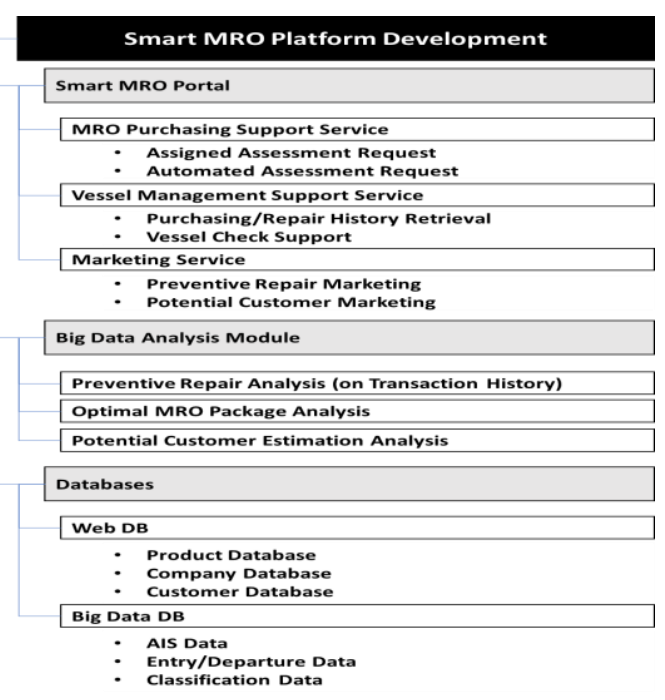

Fig. 4: Concept of Smart MRO Platform 
Big Data Analysis Module is a module that implements algorithms that perform optimal MRO package analysis, preventive maintenance analysis, and lead customer estimation analysis in conjunction with portal and database. The optimum MRO package and the preventive maintenance analysis module are mounted on the portal and the potential customer estimation module, which is used exclusively by the administrator, is separated to operate independently on the administrator's page. The database consists of a Web DB to store portal customer information and a Big Data DB to be utilized in estimating potential customers and is designed to separate and store data of different personalities.

In sum, Smart MRO Platform Development are composed of 3 major modules; Smart MRO Portal, Big Data Analysis Module, and Databases. The first module is made up of MRO Purchasing Support Service(Assigned Assessment Request, Automated Assessment Request), Vessel Management Support Service(Purchasing/Repair History Retrieval, Vessel Check Support), and Marketing Service(Preventive Repair Marketing, Potential Customer Marketing). The second module is made up of Preventive Repair Analysis (on Transaction History), Optimal MRO Package Analysis, and Potential Customer Estimation Analysis. The third module is made up of Web DB(Product Database, Company Database, Customer Database) and Big Data DB(AIS Data, Entry/Departure Data ,Classification Data)

\subsection{Development of Big Data Analysis Module}

The preventive maintenance analysis module process analyzes the data and provides information to the customer based on the customer and supplier service history. This process calculates the service required interval from the history of the customer's existing purchases service and displays the alarm message for the equipment requiring replacement. When a customer requests a quotation for the required product, the best estimate is derived through the optimum package module and the quote is provided to the customer so that the purchase can take place. In addition, this process provides ship inspection support services in connection with advance information based on the vessel information registered by the customer. This function analyzes advance data and registered vessel data to show the inspection items needed for ships and timing for preventive maintenance. In the future, CBM (Condition-Based Maintenance) technology will be able to monitor the status of products and equipment registered by customers in real time. This function enables preventive maintenance by estimating an accurate MRO when needed.

The optimal MRO package analysis process is a form of services that customers (buyers) and suppliers send and receive from the platform. This process provides an optimal package of products or services that customers need. First, after entering the model name of the product that the customer wants to purchase and requesting a quotation, the platform looks for the model name and category of the product registered in the web DB to find a vendor name or similar. Based on the data of the received estimate, the analysis result is provided to the customer by requesting a quotation from the selected vendor and combining the best suppliers. When constructing an optimal package, this module evaluates all cases of packages or combinations proposed by the supplier and presents the lowest possible values according to the ranking. In addition, the optimal MRO package analysis module is designed to consider realistic situations as an algorithm for multiple customers requesting multiple products. Customers can check the results of the optimal package through a quotation inquiry and request service after selecting the package. Once the products service is established and the supply is completed, data from the services actually occurred through the service completion approval process can be accumulated and used for analysis.

This module enables preemptive marketing by estimating ships that require MRO service among vessels scheduled to enter the port and providing information about the platform. This module analyzes AIS data, port data, and advance data to derive potential customers and the process is as follows (Figure 5).

Potential Customer Estimation

\begin{tabular}{|l|}
\hline Search target vessel \\
\hline Extract port-passing vessel \\
\hline Set the expected arrival date $(\mathrm{X}$ ) based location range \\
\hline Extract ships within the current location range \\
\hline Check potential customers' judgment \\
\hline Send promotional mail \\
\hline Connect platform \\
\hline Fig. 5: Potential Customer Estimation
\end{tabular}

(1) Search target vessel: This step searches the target vessel with potential customers based on the port number and arrival date.

(2) Extract port-passing vessel: This step shows the list of vessels with history through the port.

(3) Set the expected arrival date $(\mathrm{X})$ based location range: This step calculates the previous position by $X$ days from the date of arrival at the port. To calculate the direction of the vessel's progress, calculate the distance between the $\mathrm{X}$ and the Port, and calculate the distance between the $\mathrm{X}+1$ day position and the Port. It also sets the range of coordinates (latitude, longitude) for locations prior to $\mathrm{X}$ days for vessels entering the corresponding port.

(4) Extract ships within the current location range: This step shows the list by extracting vessels within the location range set in (3) based on the location information of the current AIS data.

(5) Check potential customers' judgment: This step estimates the vessel that needs MRO by analyzing the key data, advance inspection information, and material information of the selected vessel.

(6) Send promotional mail: This step sends a promotional mail to the system to promote the platform to potential customers.

(7) Connect platform: This step shows public relations statements and platform descriptions for convenient use when connecting platforms.

The service portal is a website that supports transactions between customers (such as the owner or ship manager) and suppliers, and additionally provides MRO related services to customers. Portal offers three large services and has six detailed functions. Some functions also work in conjunction with Big Data analytics modules. In this study, the Automatic Identification System (AIS) (Figure 6) data was used.

(1) MRO purchase support service: This service is designed to receive a customer's request for an estimated price (RFQ) of MRO products and services and connect them with the supplier. Detailed functions are as follows. (a) Request for quotation: The customer requests a quotation by designating the product and subcontractor. (b) Automated quote request: When a customer enters a large number of products, the platform automatically sends a quote request to the supplier to obtain an optimal quote package. (Based on optimal MRO package analysis module)

(2) Ship management support service: This service provides a service that manages MRO products and service history of vessels registered by customers and supports ship inspection in connection with advance data. Detailed functions are as follows.(a) MRO history check : The customer inquires and manages MRO transaction history. (b) Support for ship inspection : advance regular inspection schedule, etc are managed.

(3) Marketing service: The marketing service was developed as a service for administrators, not registered as a service portal menu. The company sends marketing messages to existing customers to induce repurchase and promotes the platform to vessels capable of making port purchases. (a) Preventive maintenance marketing : 
The client resells the equipment or parts of materials based on the MRO transaction history, considering when to replace them. (Based on Preventative Maintenance Analysis Module) (b) Prospects Marketing : AIS data are used to estimate the ships available for entry into the country and to conduct preemptive marketing for them. (Based on Lead Estimation Analysis Module)

AIS provides worldwide vessel location and operational information received from dedicated satellites. It also collects more than $10,000,000$ pieces of information from more than 126,000 vessels per day.

\section{CBM Technology Development Using AI System Concept}

\subsection{Analysis of Actual Operation Data for Ship's Equipment and Materials}

We developed and applied an algorithm to check the condition of engine room equipment by securing actual ship operation data. Ships are equipped with thousands of sensors and real-time data from those sensors are collected through databases. In this study, a model is created by learning historical normal operating data stored in the database through an artificial intelligence algorithm. By comparing the data values that are subsequently entered in real time with the forecasts of the learning model, we generate early warning when an anomaly occurs and analyze the causes.

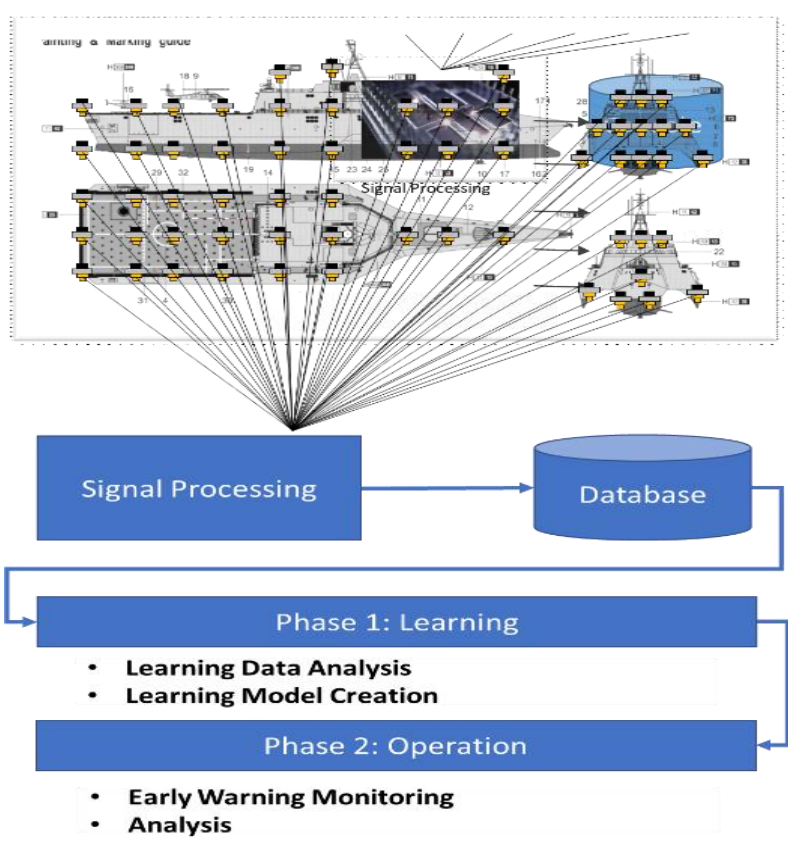

Fig. 6: Analysis on the Condition of Apparatus and Equipment using AI

Preventive maintenance means analyzing real-time signals of machine and equipment input on a regular or non-periodic basis to diagnose conditions and detect abnormalities in advance and take proper measures (Figure 6). This can prevent unexpected abnormalities in materials and equipment by diagnosing the condition of machine and equipment, and an efficient maintenance plan can be established after early detection of abnormalities. If the machine and equipment of the vessel have already failed, restoration costs and time will be high. This could disrupt the efficient operation of the vessel. Thus, it is allowed to minimize the cost and time required for maintenance/pair by accurately predicting the failure of the materials and equipment on the vessel before failure.

Data from shipping companies include a total of 175 tag data stored in the database, among which point data should be determined. The analysis included tags with empty values, tags with empty text logs, and stacked tags with no previous data to estimate the data at this point. Then we decided on 30 appropriate tags to analyze the ship's installation.

The following graph identifies the tags that have not generated anomaly alerts (Figure 7).

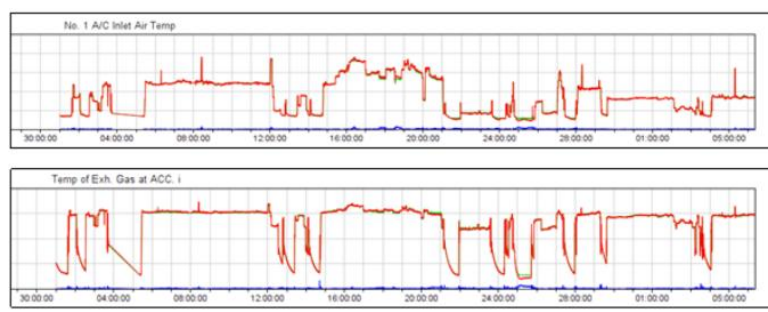

Fig. 7: Normal Data Tag

The following graph shows a large difference between the actual and predicted values of each tag (Figure 8). We have tested CBM technology based on the vessel's actual operation data. First of all, we analyzed the operation data of ship machine and equipment, and diagnosed the tags that showed abnormal symptoms. Later, through an alarmist system, we secured the basis of CBM technology. In the future, it is expected that if knowledge on actual operational data and equipment operation of the vessel is secured, not only the condition diagnosis and alarm, but also the predictions of machine and equipment will be kept intact.
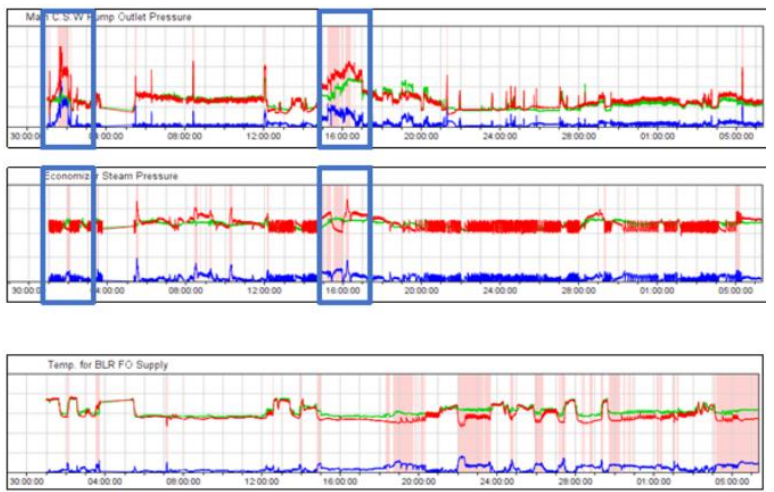

Fig. 8: Abnormal Data Tag 1 and 2

\subsection{Analysis of Vibration Data of Machine and Equip- ment}

Many of the parts that make up a vessel take up a lot of time and money to generate a random signal of failure. In the case of components that perform high-speed rotation, there is an additional risk of safety problems. The purpose of the introduction of ship mechanical and material simulators is to simulate major failures of various mechanical faults in the rotating accumulator system in these fast and rotational movements and to analyse vibration characteristics to obtain condition of machinery and materials and to predict failures. In addition, by ensuring reliable data through repeated experiments and applying the test database to actual ships, the foundation for future preventive maintenance is to be established.

The condition diagnostic simulator is optimized to detect and learn the various mechanical failure symptoms below and is useful in the same boundary conditions by minimizing changes in boundary conditions when parts are replaced. There is a limited method of analysis to use time as a variable for changing rpm during the major failure modes of the turning axis. Therefore, in this study, vibration characteristics will be analyzed to check the pulse trend with varying speeds in the time domain. The analysis items for major failures of the rotating shaft are as follows. (a) Analysis of vibration characteristics for the mismatch of axial alignment during operation (b) Analysis of vibration characteristics for eccentric load rotation movement during operation (c) Analysis of bearing 
defects (inner race defects, outer race defects, ball defects) (d) Analysis of axial running phenomenon (e) Fault gear analysis (f) Analysis of motor current signal (g) Analysis of mechanical looseness.

Based on the data learned in normal state, an abnormal signal is generated, and an alarm is generated for maintenance of the equipment. The purpose of the experiment was to analyze the characteristics of the vibration of the axial deviation and eccentric load rotation movements by using the above equipment to change the speed of the rotating accumulator system. The basic test scenario was divided into 24 test cases for each experimental variable, and the influence of the experimental variables was analyzed with a total of 44 cases including common parts.

In order to preserve precognition in abnormal areas, an operating range boundary condition using extrapolation function is desirable in time domain. It is also desirable to control the risk of abnormal segments with high sensitivity through continuous detection and learning. It is necessary to enhance resolution of signal collection and analysis beyond the limits of alarm rules under existing timebased maintenance boundary conditions. In addition, it is necessary to actively cope with the danger zone approach.

\section{Conclusion}

Like Smart MRO Portal, ship MRO service models can apply SMROP platforms to the actual business in the future. In addition, SMROP platform was operated with Korea's marine machine and equipment companies and led to MRO business through the platform for customer presences and equipment companies. At the same time, the MRO platform can be promoted to owners of dry ships to obtain MRO service in Korea. Once MRO business is established in Korea, it may expand to major overseas ports and allow local machine and equipment companies to enter overseas markets. In this study, the actual business application of the ship MRO platform could enable MRO service in the Korean shipping industry. In addition, it could increase sales of local shipping machine and equipment makers and enhance the operational competitiveness of domestic products.

\section{Acknowledgement}

This research was financially supported by Hansung University.

This work was supported by Institute for Information \& communications Technology Promotion(IITP) grant funded by the Korea government(MSIP). (No.2018-0-00705, Algorithm design and software modeling for judge fake news based on artificial intelligence)

This work was Supported by a Korea University Grant in 2015. (1.Mar.2015-28.Feb.2016)

The authors would like to thank project members and agency officers for providing project materials and interviews. This paper was supported by Korea Information Society Agency, and Daewoo Shipbuilding \& Marine Engineering Co., Ltd..

This paper was supported by Wonkwang University in 2018 .

\section{References}

[1] Chen, Hsinchun, Roger HL Chiang, and Veda C. Storey. "Business intelligence and analytics: from Big Data to big impact." MIS quarterly (2012): 1165-1188.

[2] John Walker, Saint. "Big Data: A revolution that will transform how we live, work, and think." (2014): 181-183.

[3] George, Gerard, Martine R. Haas, and Alex Pentland. "Big Data and management." (2014): 321-326.

[4] Bechtel, Christian, and James L. Patterson. "MRO partnerships: a case study." International Journal of Purchasing and Materials Management 33.2 (1997): 18-23. 